\title{
Microbiological and Sensory Characteristics of Mould-Ripened Salami under Different Packaging Conditions
}

\author{
Romina Soledad Canel ${ }^{1,2}$, \\ Sofia Guerrissi', Mariana \\ Sanchez ${ }^{3}$, Gabriela \\ Mónaco ${ }^{3}$, Federico Laich, \\ Jorge Ricardo Wagner ${ }^{1,2}$, \\ Viviana Renaud ${ }^{3}$ and \\ Vanesa Ludemann ${ }^{1,2 *}$
}

'National University of Quilmes, Roque Saenz Peña 352, 1876 Bernal, Buenos Aires, Argentina

${ }^{2}$ National Council of Scientific and Technical Research, Godoy Cruz 2290, 1033 Buenos Aires, Argentina National Institute of Industrial Technology, Av. General Paz 5445, 1650 San Martin, Buenos Aires, Argentina

${ }^{4}$ Canarian Institute of Agricultural Research, Ctra. Boquerón s/n, 38270 Santa Cruz de Tenerife, Spain

Received: 13 April 2018 Accepted: 6 February 2019

\footnotetext{
*Corresponding author:

Phone: +541143657100

Fax: +541143657101

E-mail: ludemann.vanesa@gmail.com

ORCID IDs: 0000-0002-9750-4779

(Canel), 0000-0001-5410-214X

(Guerrissi), 0000-0002-3910-2739

(Sanchez), 0000-0003-1228-6803

(Mónaco), 0000-0002-4530-7474 (Laich) 0000-0002-4892-286X (Wagner), 0000-

-0002-8832-3140 (Renaud), 0000-0001-8355-5420 (Ludemann)
}

\section{SUMMARY}

The preservation of mould-ripened salami was investigated during 48 days at $19-20^{\circ} \mathrm{C}$ under different packaging conditions: (i) high barrier film filled with air, $100 \% \mathrm{~N}_{2}$ or under vacuum, (ii) biaxially oriented polypropylene film, (iii) microperforated polyethylene film and (iv) unpackaged. Sensory, texture profile, physicochemical and microbiological analyses were performed. Fungal quantification revealed two data groups. In group 1 (consisting of salami in microperforated polyethylene film, biaxially oriented polypropylene film and unpackaged) the conidium viability was relatively constant. In group 2 (salami preserved in high barrier film filled with air, $100 \% \mathrm{~N}_{2}$ or under vacuum) the conidium viability decreased due to the absence of oxygen and the high carbon dioxide volume fraction. SEM micrographs showed micromorphological changes in fungal structure; microperforated polyethylene film, biaxially oriented polypropylene film and unpackaged conditions preserved the conidial morphology, while high barrier film filled with air, $100 \%$ $\mathrm{N}_{2}$ or vacuum conditions collapsed the hyphae and most of the conidia. Salami packed in microperforated polyethylene film and biaxially oriented polypropylene film showed the most acceptable organoleptic characteristics and lower hardness and chewiness values after packaging.

Key words: mould-ripened salami, Penicillium nalgiovense, packaging, dry sausages

\section{INTRODUCTION}

Artisanal dry fermented sausages are defined as a mix of ground meat, fatty tissues and additives such as salt, curing agents, sugar and spices stuffed into casings and subjected to fermentation and ripening processes.

Commercial mould starters are used by some industrial manufacturers to build up the typical flavour, achieve external desirable appearance and prevent the development of superficial spoilage microorganisms. These starters are mainly composed of Penicillium nalgiovense biotype 6 (1). On the other hand, products from manufacturers who do not use fungal starter cultures present greater biodiversity in the fungal species composing its mycobiota. This biodiversity depends on product type, production technology (artisanal/industrial) and the season of the year when the products are made (2-10). Traditionally, the final ripening time of dry fermented sausages depends on a compromise based on several factors, among which hardness, acidity, aroma profile and safety have major roles. These products are usually sold at room temperature in two different ways, without packaging or packaged. The first one is traditional, but the water loss and oxidative degradation are higher. The use of modified atmosphere packaging (MAP), commonly $100 \%$ nitrogen or a mixture of $70 \%$ nitrogen and $30 \%$ carbon dioxide, is a valid response to this inconvenience. In fact, under these conditions further decreases in mass due to water loss are avoided, thus offering an alternative to increase the shelf life of peeled and sliced sausages (11-13).Vacuum packaging is effective in removing oxygen, which is the main cause of food oxidation. This modality of storage is also useful to avoid further water loss of the ripened sausages (14-16). However, these types of packaging cannot be applied when the mycobiota on the surface is desirable, because the exposure to low oxygen atmosphere leads to death and degradation of the surface mycelium layer. 
A wide variety of dry fermented sausages are usually ripened and marketed with moulds. In this way, for example, in the protected geographical indication of sausages produced in Colonia Caroya (Córdoba, Argentina), the superficial fungal mycelium constitutes a typical characteristic of the product $(10,17)$.

Although there are currently markets where sausages covered with fungal surface are commercialized, the references describing these technologies are very scarce. The generation of a scientific basis to support the use of a packaging system able to adequately conserve the outer layer of mycelium on the surface of mould-ripened sausages could be of great interest to the meat industry in different parts of the world. Thus, the aim of this study is to evaluate the effects of different packaging systems on the physicochemical, microbiological and sensory properties of mould-ripened salami during storage.

\section{MATERIALS AND METHODS}

\section{Preparation of the dry fermented sausages}

Dry fermented sausages were manufactured in the pilot plant of the National Institute of Industrial Technology (INTI Carnes), Buenos Aires, Argentina. The initial sausage mixture included (in \% by mass): lean cow meat 76, pork fat 19.5 (obtained from a local meat market), sodium chloride 2.6, dextrose 0.35 , sucrose 0.35 (all from Arysa, Buenos Aires, Argentina), mix of phosphates REXFOS H (Amerex, Buenos Aires, Argentina) 0.29 , ground white pepper 0.29 , ground coriander 0.19 , garlic powder 0.10 , ground nutmeg 0.10 , sodium erythorbate 0.10 , sodium nitrate 0.04 and sodium nitrite 0.02 (all spices and preservatives were obtained from Arysa). Commercial starter culture SAGA AF2 (0.008 \% by mass; Amerex), containing Micrococcus varians, Staphylococcus carnosus, Pediococcus pentosaceus and Lactobacillus sakei was added at a final count of $7 \log$ CFU/g. This mixture was stuffed into fibrous cellulose casing (40 mm diameter; Aditrip, Buenos Aires, Argentina) to obtain sausages of approx. 270-300 g each.

A commercial starter culture of Penicillium nalgiovense (Fungal culture collection of National University of Quilmes, Buenos Aires, Argentina) was inoculated after the stuffing by dipping sausages into a spore suspension at a final count of $6 \log$ CFU/mL.

The conditions of the ripening process were: $24 \mathrm{~h}$ at $20^{\circ} \mathrm{C}$ without controlled relative humidity (RH), $36 \mathrm{~h}$ at $23^{\circ} \mathrm{C}$ and 90-95\% RH, $24 \mathrm{~h}$ at $23{ }^{\circ} \mathrm{C}$ and $80 \% \mathrm{RH}, 12 \mathrm{~h}$ at $21^{\circ} \mathrm{C}$ and $75 \%$ $\mathrm{RH}$. Finally, samples were stored at $16-18{ }^{\circ} \mathrm{C}$ and $70-75 \% \mathrm{RH}$ until 35-38\% mass loss was reached (15 days).

\section{Packaging systems}

At the end of the ripening process the sausages were packaged in thermoformed trays (AIQ S.A., San Martín, Buenos Aires, Argentina) under different packaging systems: (i) biaxially oriented polypropylene film (Argenflex, Buenos
Aires, Argentina), $40 \mu \mathrm{m}$ thickness, used for packaging with air, (ii) microperforated polyethylene, $90 \mu \mathrm{m}$ thickness and average pore size $450 \mu \mathrm{m}$ (approx. 1 pore/cm²; Argenflex) used for packaging with air, and (iii) Vac Ton film (Chemton S.A., Buenos Aires, Argentina) high barrier material, consisting of seven layers: polypropylene/tie/polyamide/ethylene vinyl alcohol (EVOH)/polyamide/tie/linear low-density polyethylene (LLDPE) with $100 \mu \mathrm{m}$ thickness. This film was used to obtain packaged product in air, $100 \% \mathrm{~N}_{2}$ and vacuum.

Twenty-five sausages were used for each packaging testing. Additionally, the same number of sausages was left unpackaged and used as control. All sausages (packaged under the different conditions and unpackaged ones) were stored at room temperature $\left(19-20^{\circ} \mathrm{C}\right)$ and analysed on days 0,12 , 24, 36 and 48 as described below.

\section{Headspace gas analysis}

Oxygen and carbon dioxide percentages were measured in duplicate (two different sausages) for each packaging condition (except for vacuum-packed) and evaluation time (4 packaging types $\times 5$ sampling times), using a gas analyser (PBI Dansensor Combi Check 9800-1; Dansensor Inc., Ringsted, Denmark).

\section{Mass loss, $\mathrm{pH}$ and water activity determinations}

Mass loss (\%), $\mathrm{pH}$ and water activity $\left(a_{\mathrm{w}}\right)$ parameters for each packaging condition were measured in duplicate at each evaluation time. The $\mathrm{pH}$ was measured in the inner core of the sausage with a glass puncture electrode using a $\mathrm{pH}$ meter (PH-206; Lutron Electronic Enterprise Co., Ltd., Taipei, Taiwan), calibrated with standard buffer solutions (Research AG, Productos Anedra, Tigre, Buenos Aires, Argentina) at $\mathrm{pH}=4.0$ (potassium hydrogen phthalate standard, $\mathrm{pH}=4.01 \pm 0.02$ at $25^{\circ} \mathrm{C}$ ) and $\mathrm{pH}=7.0$ (phosphate standard buffer, $\mathrm{pH}=7.00 \pm 0.02$ at 25 ${ }^{\circ} \mathrm{C}$ ). Additionally, $\mathrm{pH}$ was determined on the surface (casing) of the sausage after 48 days of storage in microperforated polyethylene, biaxially oriented polypropylene films and of unpackaged samples.

The $a_{\mathrm{w}}$ was measured by using LabSwift-aw portable meter (Novasina, Lachen, Switzerland). The measurement was carried out at $25^{\circ} \mathrm{C}$ and Novasina humidity standards (aqueous saturated solutions of salts: $\mathrm{LiCl} \mathrm{RH}=11 \%, \mathrm{NaBr} \mathrm{RH}=58 \%$, $\mathrm{KCl} \mathrm{RH}=84 \%$ ) were used for calibration.

\section{Microbiological analysis}

Moulds, lactic acid bacteria (LAB) and coagulase-negative catalase-positive cocci (CNCPC) from the surface of the sausages were counted (in duplicate) in each packaging system at each evaluation time. Briefly, the casing was aseptically removed from the sausages by using a sterile scalpel and tweezers, and then transferred into sterile bags containing $200 \mathrm{~mL}$ of peptone water $(0.1 \% \mathrm{~m} / \mathrm{V}$; Laboratorios Britania $\mathrm{SA}$, Buenos Aires, Argentina). Samples were homogenized in 
a stomacher (model HPS; Numak, Buenos Aires, Argentina) for $1 \mathrm{~min}$ and serially diluted. A $0.1-\mathrm{mL}$ suspension dilution was then plated and incubated onto the following media: malt extract agar (MEA; Sigma-Aldrich, Merck, St. Louis, MO, USA) at $25^{\circ} \mathrm{C}$ for 7 days, de Man, Rogosa and Sharpe (MRS; Oxoid, Basingstoke, UK) agar at $30^{\circ} \mathrm{C}$ for $48 \mathrm{~h}$ under anaerobic conditions, and mannitol salt agar (MSA; Laboratorios Britania SA) at $30^{\circ} \mathrm{C}$ for $48 \mathrm{~h}$. To prevent fungal growth, natamycin (Biotec $\mathrm{SA}$, Buenos Aires, Argentina) was added ( $200 \mathrm{mg} / \mathrm{L})$ to MRS and MSA media. Moulds, LAB and CNCPC were counted on MEA, MRS and MSA media respectively and the results were expressed as colony forming units (CFU) per $\mathrm{cm}^{2}$, taking into account the area of each analysed casing.

Fungal colonies with visibly different morphological appearance were isolated from MEA. Purified fungal isolates were identified to species level using conventional morphological taxonomic keys for foodborne moulds (18). Briefly, the isolates were grown for 7 days on MEA, Czapek yeast extract agar (CYA; HiMedia Laboratories, Mumbai, India) and $25 \%$ glycerol nitrate (G25N; HiMedia Laboratories) agar at $25^{\circ} \mathrm{C}$, and on CYA at 5 and $37^{\circ} \mathrm{C}$. Petri dishes of MEA and CYA (for incubation at $25^{\circ} \mathrm{C}$ ) were inoculated with the mould at three points, equidistant from the centre and the edge of the Petri dish and from each other. G25N agar and CYA (for incubation at 5 and $37^{\circ} \mathrm{C}$ ) were inoculated at two points of the Petri dish. After 7 days of incubation the following macroscopic examinations of the colonies were carried out: diameter $(\mathrm{mm})$, appearance (type and location of sporing structures, extent of sporulation), colour, exudate and soluble pigment production. Likewise, the following micromorphological characteristics were observed: shape, colour, texture and size of every structure of the fungus (conidia, spores, hyphae, mycelium, fruiting structures, etc.). In Penicillium isolates we observed surface texture of hyphae, length and surface texture of conidiophores, rami, metulae and phialides, number of branches (monoverticillate, biverticillate, terverticillate or quaterverticillate) and presence/absence of coremia and synnemata.

Gram stains were performed on different bacterial isolates obtained from MRS and MSA, using routine microbiological techniques. Briefly, the four basic steps of the Gram stain were: (i) staining with Gram crystal violet for $1 \mathrm{~min}$, (ii) Gram iodine for $1 \mathrm{~min}$, (iii) Gram decolourizer (95\% ethyl alcohol) for 10-30 s, (iv) Gram safranin for 30 s (all reagents were obtained from Laboratorios Britania SA). Between each step the slide with the bacterial sample was washed with water and dried in air.

Subsequent microbiological analysis was performed with the peeled sausages from each packaging according to Argentine food code (19). The assays included the detection and quantification of sulphite-reducing clostridia, incubated on sulphite agar medium (HiMedia Laboratories) at $37^{\circ} \mathrm{C}$ for $72 \mathrm{~h}$, according to ISO 15213:2003 (20), coagulase-positive Staphylococcus aureus (incubated on Baird Parker agar at $37^{\circ} \mathrm{C}$ for 48 h) and Escherichia coli using the most probable number method (21) with the following culture media: lauryl tryptose broth (incubated at $37^{\circ} \mathrm{C}$ for $48 \mathrm{~h}$ ), brilliant green lactose bile broth (incubated at $37^{\circ} \mathrm{C}$ for $48 \mathrm{~h}$ ), Escherichia coli (EC) broth (incubated at $44.5^{\circ} \mathrm{C}$ for $48 \mathrm{~h}$ ) and Levine eosin-methylene blue agar (incubated at $37^{\circ} \mathrm{C}$ for $48 \mathrm{~h}$ ) (all media were obtained from Laboratorios Britania SA). Additionally, the presence of E. coli 0157:H7 in $65 \mathrm{~g}$ of sausages, Listeria monocytogenes in $25 \mathrm{~g}$ of sausages and Salmonella spp. in $25 \mathrm{~g}$ of sausages was investigated using lateral flow test kits (Dupont, Wilmington, NC, USA).

\section{Scanning electron microscopy}

An exploratory analysis to observe the micromorphological characteristics of the fungal structures on the sausage surface after packaging was carried out by scanning electron microscopy. Analyses were performed at high resolution (2000-6000X) using a microscope, model EVO ${ }^{\circledast} 40$ XVP (Leo Electron Microscopy Ltd, Carl Zeiss, Cambridge, UK), operating at $5 \mathrm{kV}$. Samples were fixed by soaking small pieces of casings in a solution containing $50 \%$ ethanol, $35 \%$ distilled water, $10 \%$ formalin and $5 \%$ glacial acetic acid (Sigma-Aldrich, Merck). Subsequently, the samples were treated by gradually increasing volume fractions of ethanol solution $(50,75$ and $100 \%)$ at 15 -min intervals. Then, dehydration was started with acetone (Sigma-Aldrich, Merck) $50 \%$ for 15 min and $100 \%$ for $30 \mathrm{~min}$, followed by critical point drying (E3000; Polaron Instruments, Hatfield, PA, USA) using $\mathrm{CO}_{2}$. The samples were mounted on stubs. To prevent charge build-up, the samples were coated with a thin layer of gold (300 $\AA$ ) using a Pelco ${ }^{\oplus} 91000$ sputter coater model 3 (Ted Pella Inc., Redding, CA, USA), which was later evaporated using an argon plasma metal evaporator.

\section{Sensory analysis}

Sensory analysis was performed to evaluate the products according to the ISO 13299:2016 (22) on days 0, 12 and 24 of storage. The analysis was not performed after 36 and 48 days of packaging due to an excessive hardness and undesirable organoleptic characteristics of sausages packed in microperforated polyethylene and biaxially oriented polypropylene films. Six panellists (three males and three females aged between 25 and 56) were trained according to the ISO 8586-2012 (23). Sensory analysis at each time was made by the same panellists in two sessions. References for each attribute were selected and used to train them. The evaluated attributes were: external parameters (surface mycobiota, exudates, rugosity, adhesion to casing, consistency, mouldy odour and odd odour), internal appearance (ease of skin peeling, presence of crust, lean colour and fat colour), texture (cohesiveness, hardness, initial juiciness, fatty sensation and chewiness), odour, and salty, acid, off-flavour and after-taste.

Slices ( $5 \mathrm{~mm}$ thick) or whole dry fermented sausages were analysed to assay these attributes. Samples were randomly three-digit coded and presented one at a time in duplicate. A 
seven-point structured scale was used, varying from $1=$ weak to $7=$ strong. Panellists rinsed their mouth with water, apple or crackers between samples. Assessments were carried out in a quiet area free from distractions, with controlled lighting, partitions between subjects to minimize visual contact, neutral colours of the walls and odour-free surfaces.

Relationships among variables were analysed using a principal component analysis. A biplot graph was made showing factors and variables on the same graph, allowing for interpretations of the joint relations between observations and variables. The coefficient of each original variable standardized for each principal component was analysed in order to identify those with greater contribution to variability.

\section{Total volatile basic nitrogen}

The total volatile basic nitrogen (TVB-N) was evaluated in duplicate in those treatments that showed ammonia-like aromas (sausages packed in microperforated polyethylene and biaxially oriented polypropylene films) after 48 days of storage. Additionally, the unpackaged sausages were also evaluated. The surface of the sausage (casing) and the peeled sausages (inner core) were analysed by Pearson and Cox method (24), briefly, the TVB-N was released by boiling the sample directly with magnesium oxide (Sigma-Aldrich, Merck), which also prevents volatile acids from distilling over into the boric acid. The distillate was titrated with $0.1 \mathrm{M}$ hydrochloric acid (Sigma-Aldrich, Merck). The average results of three replicates from each packaging were expressed in $\mathrm{mg}$ of nitrogen per $100 \mathrm{~g}$ of sample.

\section{Texture profile analysis}

Texture profile analysis was performed using a TMS-Pro texture analyser (Food Technology Corporation, Slinfold, UK). Nine slices ( $10 \mathrm{~mm}$ thick and $30 \mathrm{~mm}$ diameter) of two sausages from each packaging were analysed up to 36 days of storage. A double compression cycle test was performed up to $50 \%$ compression of the original portion height with a $100-\mathrm{mm}$ aluminium cylinder probe, a $500-\mathrm{N}$ load cell and $300 \mathrm{~mm} / \mathrm{min}$ cross-head speed. The sample temperature was $10-15^{\circ} \mathrm{C}$. The following parameters were quantified: hardness $(\mathrm{N})$, i.e. maximum force required to compress the sample, elasticity $(\mathrm{mm})$, i.e. the ability of the sample to recover its original shape after deforming force was removed, and chewiness ( $\mathrm{mJ})$, i.e. the energy needed to chew a solid food until it is ready for swallowing.

\section{Statistical analysis}

The analysis of variance (ANOVA) was carried out using the InfoStat software v. 2017 (25). Mean values were compared using the Tukey's test to determine their statistical significance. Any probability less than or equal to 0.05 was considered significant.

\section{RESULTS AND DISCUSSION}

\section{Microbial counts and scanning electron micrographs}

Penicillium nalgiovense was competitive against native mycobiota achieving a homogeneous white fungal surface on the products prior to packaging. Quantification of filamentous fungi on the sausage surface revealed two data groups (Fig. 1a). In group 1 (consisting of salami packed in microperforated polyethylene and biaxially oriented polypropylene films and unpackaged ones), fungal population $\left(\mathrm{CFU} / \mathrm{cm}^{2}\right)$ was relatively stable over time (approx. 7 log CFU/cm²). In group 2 (salami packed in high barrier film filled with air, $100 \% \mathrm{~N}_{2}$ or under vacuum), a reduction in the fungal population counts was observed during storage. After 48 days of storage, fungal count in sausages packaged in high barrier film with air was 6 log CFU/ $\mathrm{cm}^{2}$ lower than the initial count (0 packaging days), while this reduction was by $4 \mathrm{log} \mathrm{CFU} / \mathrm{cm}^{2}$ in sausages packed under vacuum and by $3 \log \mathrm{CFU} / \mathrm{cm}^{2}$ in samples packed in $\mathrm{N}_{2}$.
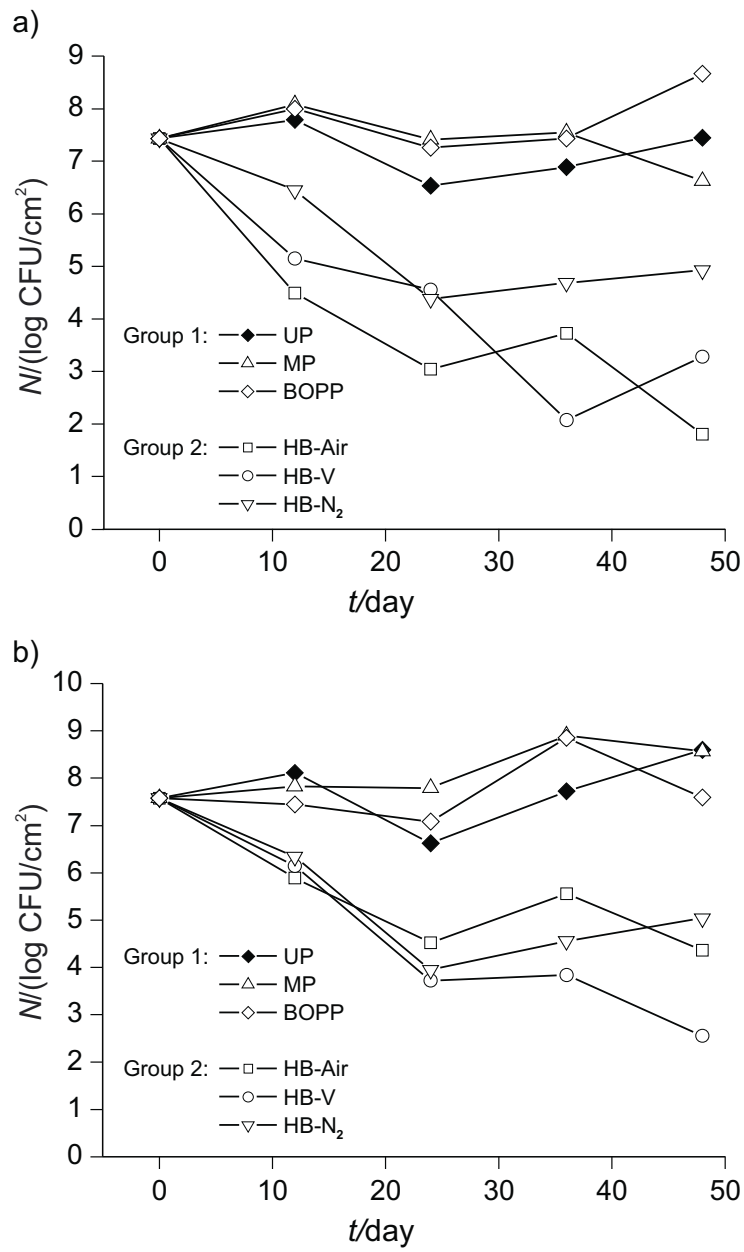

Fig. 1. Average values of: a) fungal count and b) coagulase-negative catalase-positive cocci (CNCPC) count on sausages in different packaging systems. Maximum standard deviation: $5 \%$. UP=unpackaged samples, $\mathrm{MP}=$ microperforated film, $\mathrm{BOPP}=$ biaxially oriented polypropylene film, HB-Air=high barrier film with air, HB-V=high barrier film with vacuum, $\mathrm{HB}-\mathrm{N}_{2}=$ high barrier film with $100 \%$ nitrogen 
With respect to the evaluation of the coagulase-negative catalase-positive cocci (CNCPC), a similar pattern was observed (Fig. 1b). In group 1, counts did not change during the storage period (approx. $7 \mathrm{log} \mathrm{CFU} / \mathrm{cm}^{2}$ ). In contrast, in group 2, the counts in sausages packed in high barrier film filled with air, $100 \% \mathrm{~N}_{2}$ or under vacuum after 48 days of storage were respectively 2, 3 and $5 \log C F U / \mathrm{cm}^{2}$ lower than the counts at the initial time (0 packaging days).

For LAB counts, a reduction of $2 \log \mathrm{CFU} / \mathrm{cm}^{2}$ was observed in samples packed in high barrier film with air, $\mathrm{N}_{2}$ or under vacuum and in microperforated polyethylene film after 48 days of storage (Fig. 2). In biaxially oriented polypropylene film and under unpackaged conditions, LAB counts did not change between the initial time and 48 days $\left(7 \mathrm{log} \mathrm{CFU} / \mathrm{cm}^{2}\right)$. It is noteworthy that none of the packaging conditions tested achieved greater CNCPC and LAB counts than the unpackaged sausages.
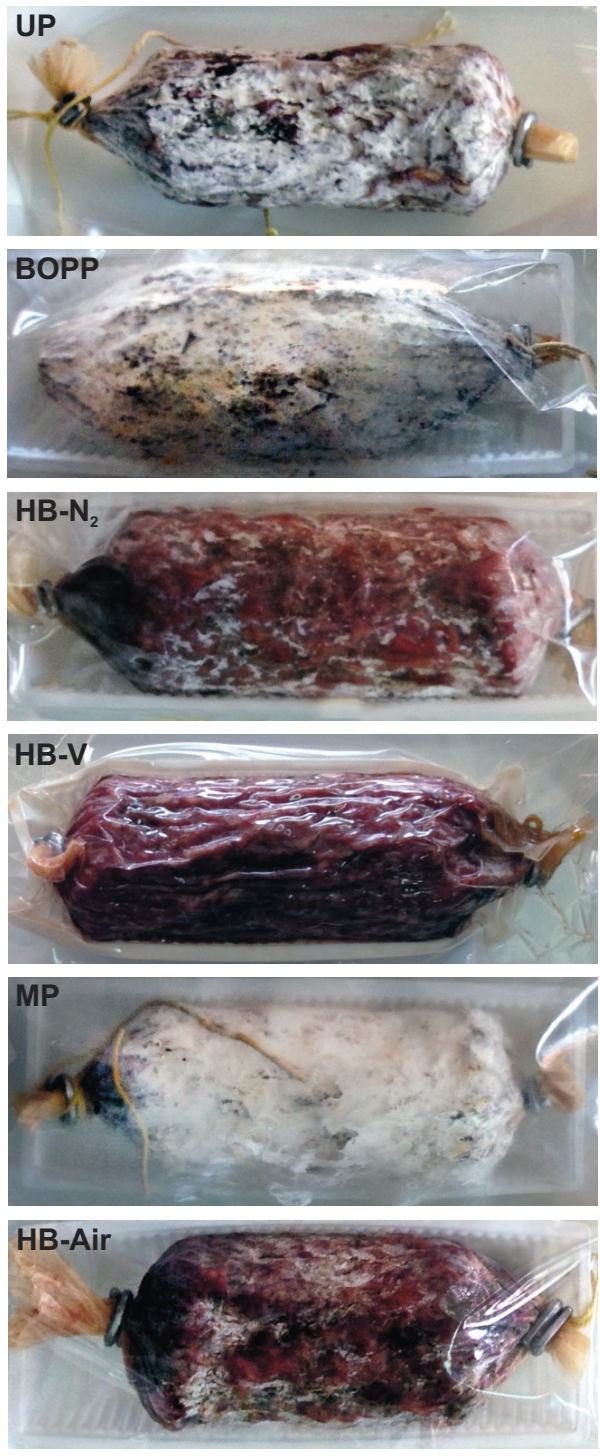

Fig. 2. Dry fermented sausages under different packaging conditions during 36 days. UP=unpackaged samples, BOPP=biaxially oriented polypropylene film, HB- $\mathrm{N}_{2}=$ high barrier film with $100 \%$ nitrogen, $\mathrm{HB}-\mathrm{V}=$ high barrier film with vacuum, $\mathrm{MP}=$ microperforated film, $\mathrm{HB}$ -Air=high barrier film with air
With respect to the fungal biota, the counts were congruent with the external appearance of the sausages. SEM micrographs at the initial time (0 packaging days) show the typical micromorphology characteristics of Penicillium nalgiovense, i.e. tubular shapes with smooth surface, terverticillate penicillin and subspheroidal conidia of $2.5 \mu \mathrm{m}$ in diameter. Likewise, these penicilli were surrounded by cocci of about $0.5 \mu \mathrm{m}$ in diameter (Fig. 3).
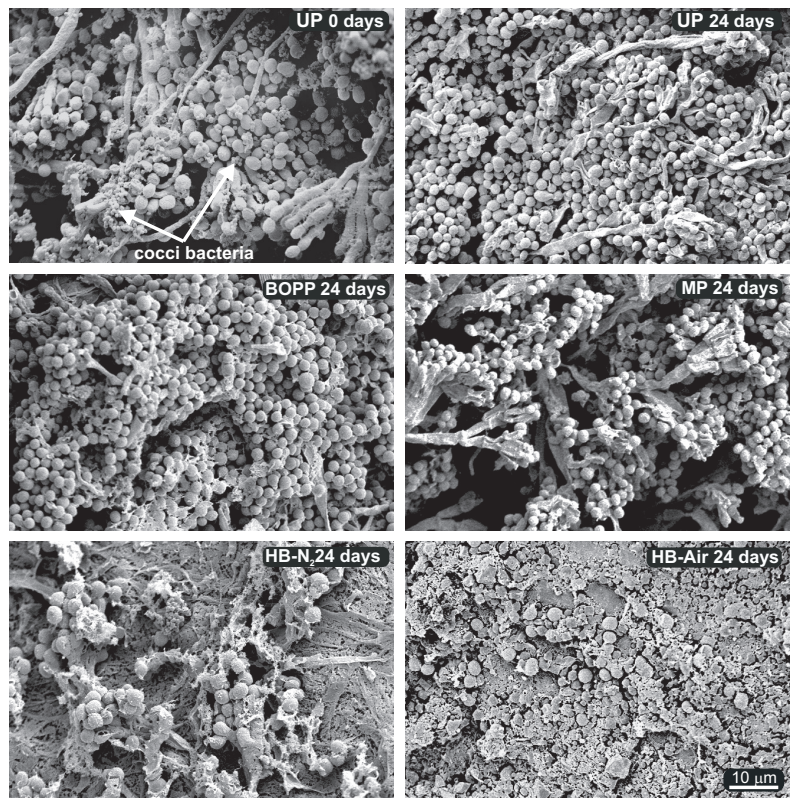

Fig. 3. Scanning electron micrographs (SEM) of dry sausage surface under different packaging conditions ( 0 and 24 days). UP=unpackaged samples, BOPP=biaxially oriented polypropylene film, $\mathrm{MP}=\mathrm{mi}-$ croperforated film, $\mathrm{HB}-\mathrm{N}_{2}=$ high barrier film with $100 \%$ nitrogen, $\mathrm{HB}$ Air=high barrier film with air

After 24 days of storage, samples from all packaging systems showed morphological changes of the fungal structure. In microperforated polyethylene film, biaxially oriented polypropylene film and unpackaged conditions, crinkled hyphae were observed, while conidia retained their morphology (Fig. 3). In spite of these micromorphological alterations, the CFU/ $\mathrm{cm}^{2}$ count remained broadly unchanged with time (Fig. 1, group 1), probably because the viability of the conidia remained unaltered. On the other hand, the micromorphological alterations of the fungal surface of sausages packaged in high barrier film filled with air or $\mathrm{N}_{2}$ (Fig. 3) were associated with the $\mathrm{CFU} / \mathrm{cm}^{2}$ count reduction (Fig. 1, group 2). Probably, the oxygen absence and the high carbon dioxide volume fraction (Table 1) caused a viability decrease (low count of $\mathrm{CFU} / \mathrm{cm}^{2}$ ). In both packaging systems (high barrier film filled with air or $\mathrm{N}_{2}$ ), SEM micrographs showed a high disintegration of the fungal hyphae; however, in sausages packaged in high barrier film filled with $\mathrm{N}_{2}$ some conidia remained morphologically unaffected (Fig. 3). Regarding the sausages packaged under vacuum, the disintegration of the mycelium was greater than in the case of sausages preserved in high barrier film with air (data not shown). 
Table 1. Volume fractions of headspace gases under different packaging conditions during storage

\begin{tabular}{|c|c|c|c|c|c|c|}
\hline \multirow{3}{*}{ Packaging system } & \multirow{3}{*}{ Gas } & \multicolumn{5}{|c|}{$t$ (storage)/day } \\
\hline & & 0 & 12 & 24 & 36 & 48 \\
\hline & & \multicolumn{5}{|c|}{$\varphi / \%$} \\
\hline \multirow{3}{*}{ HB-Air } & $\mathrm{O}_{2}$ & 20.04 & 0.18 & 0.19 & 0.50 & 0.76 \\
\hline & $\mathrm{CO}_{2}$ & 0.50 & 22.60 & 25.20 & 30.10 & 30.30 \\
\hline & $\mathrm{N}_{2}$ & 79.50 & 77.20 & 74.60 & 69.40 & 68.98 \\
\hline \multirow{3}{*}{ BOPP } & $\mathrm{O}_{2}$ & 20.04 & 3.85 & 1.63 & 1.50 & 1.06 \\
\hline & $\mathrm{CO}_{2}$ & 0.50 & 10.80 & 9.70 & 8.50 & 6.34 \\
\hline & $\mathrm{N}_{2}$ & 79.50 & 85.30 & 88.70 & 90.00 & 92.90 \\
\hline \multirow{3}{*}{$\mathrm{HB}-\mathrm{N}_{2}$} & $\mathrm{O}_{2}$ & 0.50 & 0.54 & 0.21 & 0.20 & 0.15 \\
\hline & $\mathrm{CO}_{2}$ & 7.50 & 17.10 & 18.90 & 25.00 & 25.00 \\
\hline & $\mathrm{N}_{2}$ & 92.00 & 82.40 & 80.90 & 74.80 & 74.85 \\
\hline \multirow{3}{*}{ MP } & $\mathrm{O}_{2}$ & 20.04 & 20.00 & 19.96 & 20.30 & 20.30 \\
\hline & $\mathrm{CO}_{2}$ & 0.50 & 0.50 & 0.50 & 0.50 & 0.50 \\
\hline & $\mathrm{N}_{2}$ & 79.50 & 79.50 & 79.50 & 79.20 & 79.20 \\
\hline
\end{tabular}

Data are mean values of two different sausages and three replications per sausage. All data show a standard deviation $<0.5 \%$. HB-Air=high barrier film with air, BOPP=biaxially oriented polypropylene film, HB-N $=$ high barrier film with $100 \%$ nitrogen, MP=microperforated film

Microbiological criteria required by the Argentine food code (19) were fulfilled during the entire packaging period, namely: count of sulphite-reducing bacteria $<100$ CFU/g, coagulase-positive staphylococci $<100 \mathrm{CFU} / g$ and $\mathrm{E}$. coli $<3 \mathrm{MP}$ $\mathrm{N} / \mathrm{g}$. The absence of pathogenic microorganisms according to the Argentine food code was also verified, at initial time with $N=5$ sausages, E. coli O157:H7 was absent in a 65-gramme sample, and Listeria monocytogenes and Salmonella spp. were absent from a 25-gramme sample.
Mass loss, pH, water activity, headspace gas analysis and total volatile basic nitrogen

Sausage mass loss and water activity changed slightly after packaging and storage for 48 days, except in the unpackaged sausages, which showed a significant reduction of both parameters (Table 2).

The $\mathrm{pH}$ of the sausages at the start of storage was 4.99. After 48 days of packaging, the $\mathrm{pH}$ increased slightly (values between 5.5 and 5.6) in sausages packaged in high barrier film

Table 2. Physicochemical parameters of sausages in different packaging systems after $0,12,24,36$ and 48 days

\begin{tabular}{|c|c|c|c|c|c|}
\hline \multirow{3}{*}{ Packaging system } & \multicolumn{5}{|c|}{$t($ storage $) /$ day } \\
\hline & 0 & 12 & 24 & 36 & 48 \\
\hline & \multicolumn{5}{|c|}{$\mathrm{pH}$} \\
\hline UP & $4.99 \pm 0.06$ & $5.37 \pm 0.06$ & $5.36 \pm 0.08$ & $5.37 \pm 0.03$ & $5.63 \pm 0.01$ \\
\hline MP & $4.99 \pm 0.06$ & $5.47 \pm 0.11$ & $6.25 \pm 0.01$ & $6.39 \pm 0.08$ & $6.67 \pm 0.09$ \\
\hline BOPP & $4.99 \pm 0.06$ & $5.43 \pm 0.07$ & $5.62 \pm 0.01$ & $6.4 \pm 0.06$ & $6.31 \pm 0.14$ \\
\hline $\mathrm{HB}-\mathrm{N}_{2}$ & $4.99 \pm 0.06$ & $5.34 \pm 0.04$ & $5.47 \pm 0.05$ & $5.52 \pm 0.02$ & $5.55 \pm 0.05$ \\
\hline HB-V & $4.99 \pm 0.06$ & $5.14 \pm 0.03$ & $5.57 \pm 0.03$ & $5.26 \pm 0.08$ & $5.54 \pm 0.02$ \\
\hline \multirow[t]{2}{*}{ HB-Air } & $4.99 \pm 0.06$ & $5.16 \pm 0.04$ & $5.49 \pm 0.04$ & $5.43 \pm 0.08$ & $5.62 \pm 0.05$ \\
\hline & \multicolumn{5}{|c|}{$a_{w}$} \\
\hline UP & $0.9 \pm 0.01$ & $0.8 \pm 0.02$ & $0.75 \pm 0.01$ & $0.71 \pm 0.01$ & $0.67 \pm 0.02$ \\
\hline MP & $0.9 \pm 0.01$ & $0.9 \pm 0.01$ & $0.89 \pm 0.01$ & $0.88 \pm 0.02$ & $0.89 \pm 0.01$ \\
\hline BOPP & $0.9 \pm 0.01$ & $0.89 \pm 0.01$ & $0.89 \pm 0.01$ & $0.9 \pm 0.01$ & $0.88 \pm 0.02$ \\
\hline $\mathrm{HB}-\mathrm{N}_{2}$ & $0.9 \pm 0.01$ & $0.9 \pm 0.01$ & $0.88 \pm 0.01$ & $0.89 \pm 0.02$ & $0.89 \pm 0.01$ \\
\hline HB-V & $0.9 \pm 0.01$ & $0.9 \pm 0.01$ & $0.89 \pm 0.01$ & $0.88 \pm 0.01$ & $0.88 \pm 0.01$ \\
\hline \multirow[t]{2}{*}{ HB-Air } & $0.9 \pm 0.01$ & $0.9 \pm 0.01$ & $0.88 \pm 0.02$ & $0.88 \pm 0.01$ & $0.88 \pm 0.02$ \\
\hline & \multicolumn{5}{|c|}{$w($ mass loss $) / \%$} \\
\hline UP & $37.7 \pm 0.8$ & $46.1 \pm 0.3$ & $50.1 \pm 0.7$ & $52.8 \pm 0.6$ & $53.0 \pm 0.2$ \\
\hline MP & $35.7 \pm 0.6$ & $38.4 \pm 0.4$ & $39.1 \pm 0.2$ & $38.5 \pm 0.4$ & $39.4 \pm 0.4$ \\
\hline BOPP & $35.8 \pm 0.7$ & $37.1 \pm 0.3$ & $36.6 \pm 0.5$ & $39.0 \pm 0.2$ & $36.4 \pm 0.5$ \\
\hline $\mathrm{HB}-\mathrm{N}_{2}$ & $36.0 \pm 0.7$ & $36.2 \pm 0.7$ & $35.3 \pm 0.9$ & $36.4 \pm 0.9$ & $36.5 \pm 0.8$ \\
\hline HB-V & $36.5 \pm 0.8$ & $35.9 \pm 0.1$ & $36.9 \pm 0.4$ & $37.9 \pm 0.5$ & $36.9 \pm 0.6$ \\
\hline HB-Air & $36.7 \pm 0.8$ & $37.1 \pm 0.3$ & $37.1 \pm 0.8$ & $36.4 \pm 0.8$ & $35.9 \pm 0.5$ \\
\hline
\end{tabular}

Data are mean value \pm standard deviation of three independent measurements (inner core of sausages). UP=unpackaged, $\mathrm{MP}=$ microperforated film, BOPP=biaxially oriented polypropylene film, HB- $\mathrm{N}_{2}=$ high barrier film with $100 \%$ nitrogen, $\mathrm{HB}-\mathrm{V}=$ vacuum packaging, $\mathrm{HB}-\mathrm{Air}=\mathrm{high}$ barrier film with air 
filled with air, $100 \% \mathrm{~N}_{2}$ or under vacuum and in unpackaged sausages. Consistent results were reported by Tabanelli et al. (13) on Milano-type dry fermented sausages. Nevertheless, the $\mathrm{pH}$ of samples packaged in biaxially oriented polypropylene film and microperforated polyethylene film showed a substantial increase, reaching values of 6.5 on average (Table 2). This increase can be attributed to fungal metabolic activity $(26,27)$ due to the presence of oxygen and high humidity. At this storage time (48 days), in microperforated polyethylene film packages the atmosphere composition $\left(20.30 \% \mathrm{O}_{2}\right.$ and $\left.0.50 \% \mathrm{CO}_{2}\right)$ did not change, while in the biaxially oriented polypropylene film packages, the volume fraction of oxygen decreased from 20.04 to $1.06 \%$, and of carbon dioxide increased from 0.50 to $6.34 \%$ (Table 1). This low oxygen volume fraction in biaxially oriented polypropylene film packages proved to be suitable for maintaining the fungal conidium viability according to previous literature, which shows that different species have successfully grown under oxygen volume fraction of approx. 1 $\%$ (28-31). However, SEM micrographs of samples packaged in biaxially oriented polypropylene film, microperforated polyethylene film and the unpackaged treatment (Fig. 3) showed crinkled hyphae after 24 days. Collapsed hyphae could cause cell damage with loss of cytoplasmic material. In this sense the high metabolic activity could be due to exogenous enzymes previously produced in addition to those released by cell disruption. Nevertheless, in the unpackaged samples the enzyme activity decreased due to the low water activity $\left(a_{\mathrm{w}}=0.75\right.$; Table 2), which could act as a limiting factor (32).

In high barrier films (air and $\mathrm{N}_{2}$ ) 12 days after packaging, the volume fraction of oxygen was lower than $0.6 \%$ and of carbon dioxide was around $20 \%$. After 36 days of storage, the carbon dioxide volume fraction was higher than $25 \%$ (Table 1). This could explain the fungal spore viability reduction in group 2 (Fig. 1). Dry meat products are widely packaged in modified atmosphere $\left(70 \% \mathrm{~N}_{2}\right.$ and $\left.30 \% \mathrm{CO}_{2}\right)$ to inhibit microbial growth and increase the shelf life of the product $(11,12,33)$. The use of high barrier material (Vac Ton) films allows the highest $\mathrm{CO}_{2} \mathrm{ac}-$ cumulation levels due to different metabolic pathways according to Ščetar et al. (34).

The high metabolic activity of moulds in microperforated polyethylene and biaxially oriented polypropylene films was evidenced by the strong ammonia-like smell (perceived by the sensorial panel as odd odour) and the high TVB-N mass fractions in the inner core of sausages after 48 days of storage ( 250 and $200 \mathrm{mg} / 100 \mathrm{~g}$, respectively; data not shown). TVB-N in the unpackaged sausages was $80 \mathrm{mg} / 100 \mathrm{~g}$, similar to the values reported in well-ripened Italian sausages (3537). Higher amount of ammonia increased $\mathrm{pH}$ values (Table 2), since the mass fraction of volatile nitrogen in meat is mainly influenced by ammonia concentration (38). It is possible that the combined metabolic activity of microorganisms (bacteria and moulds) increases the production of TVB-N, taking into account the ability of CNCPC and LAB to degrade amino acids and produce volatile nitrogen compounds, as it has been demonstrated by several authors $(36,39,40)$.
A significant increase of the TVB-N was observed on the surface (casing) of the sausage compared to the inner part. TVB-N mass fractions measured at the surface of the sausages packaged in biaxially oriented polypropylene film, microperforated polyethylene film and in unpackaged conditions were up to $30 \%$ higher than those observed in the inner part of the product $(330,275$ and $99.5 \mathrm{mg} / 100 \mathrm{~g}$, respectively; data not shown). Similar results were observed for the $\mathrm{pH}$ values of the sausage surface; samples in microperforated polyethylene and biaxially oriented polypropylene films had $\mathrm{pH}>7$ (data not shown). These results suggest that the surface fungal growth could be the main reason for the sausage spoilage. Regarding the unpackaged sausage, a drastic $a_{\mathrm{w}}$ reduction during storage leads to the conclusion that even if the fungus remains viable over time, it does not have a high metabolic activity (constant pH) (Table 2).

\section{Hardness, elasticity and chewiness of sausages}

Table 3 shows the texture profile analysis parameters during storage using different packaging systems, as well as the results of Tukey's test. The values at the start of the storage time (0 packaging days) for hardness $((133 \pm 7) \mathrm{N})$, elasticity $((4.3 \pm 0.1)$ $\mathrm{mm})$ and chewiness $((378 \pm 24) \mathrm{mJ})$ were consistent with the results reported by Herrero et al. (41).

Hardness was relatively stable over time (high barrier film, microperforated polyethylene film and biaxially oriented polypropylene film), except for the sausages in biaxially oriented polypropylene film after 36 days, which showed a significant-

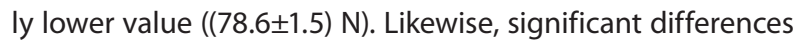
$(p<0.05)$ were observed among treatments after 12 days of storage; the hardness of unpackaged sausages was significantly higher than in the other treatments, while the sausages packaged in biaxially oriented polypropylene film showed the lowest values after 36 days of storage.

Elasticity increased in packaged sausages (high barrier film, microperforated polyethylene film and biaxially oriented polypropylene film) after 24 days of storage. There were no significant differences $(p<0.05)$ among packaged sausages (high barrier film, biaxially oriented polypropylene film and microperforated polyethylene film) after 24 days of storage, while after 36 days samples in biaxially oriented polypropylene film showed the highest value. The data for unpackaged sausages were significantly lower than for the other treatments after 12 days of storage.

No significant differences were detected in the chewiness of the high barrier-packaged sausages during storage (except for day 12). However, sausages packaged in biaxially oriented polypropylene and microperforated polyethylene films had significantly lower chewiness $(p<0.05)$ after 36 days of storage than at the beginning. Also, no significant differences were detected between the samples packaged in high barrier and microperforated polyethylene films after 24 days of storage, while after 36 days samples packaged in biaxially oriented polypropylene film had the lowest chewiness. The highest value was recorded in unpackaged sausages after 24 days of storage. 
Table 3. Texture profile analysis of the ripened sausages under different packaging conditions during storage at $20^{\circ} \mathrm{C}$

\begin{tabular}{|c|c|c|c|c|c|}
\hline \multirow{2}{*}{ Parameter } & \multirow{2}{*}{ Packaging system } & \multicolumn{4}{|c|}{$t$ (storage)/day } \\
\hline & & 0 & 12 & 24 & 36 \\
\hline \multirow{6}{*}{ Hardness/N } & UP & $(133 \pm 7)^{\mathrm{a}}$ & $(231 \pm 14)^{\mathrm{bB}}$ & $(459 \pm 14)^{\mathrm{cC}}$ & n.d. \\
\hline & MP & $(133 \pm 7)^{\mathrm{a}}$ & $(117 \pm 13)^{\mathrm{abA}}$ & $(129 \pm 21)^{\mathrm{abA}}$ & $(111 \pm 6)^{\mathrm{bB}}$ \\
\hline & BOPP & $(133 \pm 7)^{\mathrm{a}}$ & $(137 \pm 7)^{\mathrm{aA}}$ & $(163 \pm 6)^{\mathrm{bB}}$ & $(78.6 \pm 1.5 .)^{\mathrm{CA}}$ \\
\hline & HB-Air & $(133 \pm 7)^{\mathrm{a}}$ & $(130 \pm 18)^{\mathrm{aA}}$ & $(135 \pm 9)^{\mathrm{aA}}$ & $(130 \pm 3)^{\mathrm{aBC}}$ \\
\hline & $\mathrm{HB}-\mathrm{N}_{2}$ & $(133 \pm 7)^{\mathrm{a}}$ & $(116 \pm 11)^{\mathrm{bA}}$ & $(134 \pm 7)^{\mathrm{aA}}$ & $(132 \pm 11)^{\mathrm{ac}}$ \\
\hline & $\mathrm{HB}-\mathrm{V}$ & $(133 \pm 7)^{\mathrm{ab}}$ & $(118 . \pm 8)^{\mathrm{aA}}$ & $(142 \pm 8)^{\mathrm{bA}}$ & $(138 \pm 18)^{\mathrm{bC}}$ \\
\hline \multirow{5}{*}{ Elasticity/mm } & UP & $(4.3 \pm 0.1)^{a}$ & $(3.2 \pm 0.09)^{\mathrm{bA}}$ & $(3.6 \pm 0.1)^{\mathrm{cA}}$ & n.d. \\
\hline & MP & $(4.3 \pm 0.1)^{a}$ & $(4.0 \pm 0.1)^{\mathrm{cc}}$ & $(4.41 \pm 0.07)^{\mathrm{abB}}$ & $(4.5 \pm 0.1)^{\mathrm{bA}}$ \\
\hline & BOPP & $(4.3 \pm 0.1)^{a}$ & $(3.9 \pm 0.08)^{\mathrm{bBC}}$ & $(4.4 \pm 0.13)^{\mathrm{aB}}$ & $(4.99 \pm 0.08)^{C B}$ \\
\hline & HB-Air & $(4.3 \pm 0.1)^{a}$ & $(3.7 \pm 0.2)^{\mathrm{CB}}$ & $(4.55 \pm 0.07)^{\mathrm{bB}}$ & $(4.6 \pm 0.1)^{\mathrm{bA}}$ \\
\hline & $\mathrm{HB}-\mathrm{N}_{2}$ & $(4.3 \pm 0.1)^{a}$ & $(3.98 \pm 0.07)^{\mathrm{cC}}$ & $(4.4 \pm 0.1)^{\mathrm{abB}}$ & $(4.6 \pm 0.1)^{\mathrm{bA}}$ \\
\hline \multirow{7}{*}{ Chewiness/mJ } & $\mathrm{HB}-\mathrm{V}$ & $(4.3 \pm 0.1)^{a}$ & $(4.01 \pm 0.09)^{\mathrm{cC}}$ & $(4.4 \pm 0.1)^{\mathrm{abB}}$ & $(4.6 \pm 0.1)^{\mathrm{bA}}$ \\
\hline & UP & $(378 \pm 24)^{a}$ & $(342 \pm 15)^{\mathrm{aB}}$ & $(783 \pm 39)^{\mathrm{bc}}$ & n.d. \\
\hline & MP & $(378 \pm 24)^{a}$ & $(273 \pm 31)^{\mathrm{CA}}$ & $(355 \pm 52)^{\mathrm{abA}}$ & $(311 \pm 26)^{\mathrm{cb} A B}$ \\
\hline & BOPP & $(378 \pm 24)^{a}$ & $(307 \pm 20)^{\mathrm{bB}}$ & $(454 \pm 12)^{\mathrm{CB}}$ & $(244 \pm 8)^{\mathrm{dA}}$ \\
\hline & HB-Air & $(378 \pm 24)^{a}$ & $(281 \pm 43)^{\mathrm{bA}}$ & $(392 \pm 27)^{\mathrm{aA}}$ & $(386 \pm 18)^{a B C}$ \\
\hline & $\mathrm{HB}-\mathrm{N}_{2}$ & $(378 \pm 24)^{a}$ & $(271 \pm 26)^{\mathrm{bA}}$ & $(384 \pm 18)^{\mathrm{aA}}$ & $(386 \pm 35)^{a B C}$ \\
\hline & $\mathrm{HB}-\mathrm{V}$ & $(378 \pm 24)^{a}$ & $(276 \pm 14)^{\mathrm{bA}}$ & $(390 \pm 26)^{\mathrm{aA}}$ & $(408 \pm 71)^{\mathrm{ac}}$ \\
\hline
\end{tabular}

Mean values followed by different lower-case letters within a row are significantly different (Tukey's test, $p<0.05)$. Mean values followed by different capital letters within a column (within each parameter) are significantly different (Tukey's test, $p<0.05$ ). n.d.=not determined; $\mathrm{UP}=$ unpackaged, $\mathrm{MP}=$ microperforated film, $\mathrm{BOPP}=$ biaxially oriented polypropylene film, $\mathrm{HB}$-Air=high barrier film with air, $\mathrm{HB}-\mathrm{N}_{2}=$ high barrier film with $100 \%$ nitrogen, $\mathrm{HB}-\mathrm{V}=$ vacuum packaging

In general, at the end of storage samples packaged in biaxially oriented polypropylene and microperforated polyethylene films had similar properties. Samples packaged in biaxially oriented polypropylene film had the lowest values of hardness and chewiness and the highest values of elasticity, probably because of excessive metabolic activity (high pH and TVB-N values) observed in these samples.

\section{Sensory evaluation}

Sensory analysis after 36 and 48 days was not performed due to the exceptional hardness of the unpackaged sausages and the undesirable organoleptic characteristics of the sausages packaged in biaxially oriented polypropylene and microperforated polyethylene films. Consequently, further analysis only refers to 0,12 and 24 days of storage. Contributions of each attribute to variability in dimensions 1 and 2 of the first PCA were analysed and attributes with a total contribution equal to or higher than 0.30 were selected for second PCA (cophenetic correlation coefficient: 0.97 ). Thus, 12 attributes of the original 21 were selected. From the second PCA, a biplot for individual and variable factors was obtained (Fig. 4). The presence of crust, chewiness, exudates, odd odour, hardness, adhesion to casing, surface mycobiota, consistency, rugosity, lean colour, acid taste and off-flavour explained $74.3 \%$ of the total variability. Regarding surface mycobiota, exudates and adhesion to casing attributes, two groups can be identified: first unpackaged, microperforated polyethylene film and biaxially oriented polypropylene film packaging systems, and second high barrier package (Fig. 4). The first group had the highest count of surface mycobiota (Fig. 1a), while the highest values of superficial exudates were in high barrier packages, which is probably due to the fungal count and cell lysis (Fig. 1b).

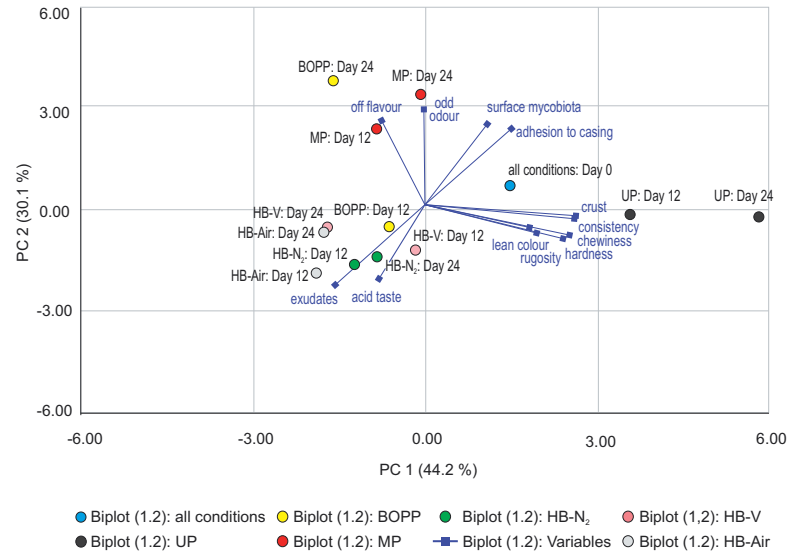

Fig. 4. Principal component analysis (PCA) of sensory characteristics of dry fermented sausages in different packaging systems after 0,12 and 24 days of storage (biplot). BOPP=biaxially oriented polypropylene film, HB-V=high barrier film with vacuum, $\mathrm{HB}-\mathrm{N}_{2}=$ high barrier film with $100 \%$ nitrogen, HB-Air=high barrier film with air, MP=microperforated film, UP=unpackaged samples

The same two groups had similar off-flavour and odd odour attributes, with the exception of unpackaged treatment in the second group. This result was probably due to the high mould count detected in samples packaged in biaxially oriented polypropylene and microperforated polyethylene films (Fig. 4). The odd odour could be due to high values of TVB-N, according to lacumin et al. (37), who obtained similar results in spoiled goose sausages.

Three groups can be identified according to the modifications of texture attributes and some external appearance attributes (consistency and superficial texture) throughout storage: group 1: high barrier packaged samples, group 2: samples packaged in biaxially oriented polypropylene and 
microperforated polyethylene films, and group 3: unpackaged samples. Group 2 was closer to the initial conditions ( 0 days after packaging), while unpackaged sausages had higher hardness and chewiness values (Fig. 4). These results correlate with the major mass loss and the texture profile analysis values obtained in unpackaged samples and with the $\mathrm{pH}$ increase (proteolysis) detected in samples packaged in biaxially oriented polypropylene and microperforated polyethylene films.

\section{CONCLUSIONS}

The results strongly suggest that the use of a high barrier material in preventing the loss of water from the product causes a drastic modification of the atmosphere during storage, which leads to a loss of cellular integrity of the filamentous fungi. Conversely, biaxially oriented polypropylene and microperforated polyethylene films allow oxygen exchange with the outside air, and at the same time create a microenvironment with higher water content, maintaining higher viability of the filamentous fungi. Therefore, it is possible to increase shelf life of dry fermented sausages with superficial fungal development, using appropriate packaging conditions. A future challenge is to reduce fungal metabolic activity throughout storage to avoid undesirable organoleptic changes (excessive mould odour and odd odour). Therefore, further research would be interesting so as to study the effect of storage temperature on fungal growth to extend the shelf life of sausages using biaxially oriented polypropylene and microperforated polyethylene films.

\section{ACKNOWLEDGEMENTS}

The authors are grateful to Nahir Arena and Ernesto Gramajo Harguindeguy for manufacturing and ripening of sausages, María Sol Gonzalez Piazza for texture profile analyses, Cecilia Kainz for technical support (INTI Carnes) and Juan Francisco Delgado for statistical assistance. This work was supported by the National University of Quilmes, Argentina (Program 1410/15).

\section{REFERENCES}

1. Leistner L. Mould-fermented foods: recent development. Food Biotechnol.1990;4(1):433-41. https://doi.org/10.1080/08905439009549755

2. Andersen SJ. Composition changes in surface mycoflora during ripening of naturally fermented sausages. J Food Protect.1995;58(4):426-9.

https://doi.org/10.4315/0362-028X-58.4.426

3. López-Díaz TM, Santos JA, García-López ML, Otero A. Surface mycoflora of a Spanish fermented meat sausage and toxigenicity of Penicillium isolated. Int J Food Microbiol. 2001;68(1-2):69-74.

https://doi.org/10.1016/S0168-1605(01)00472-X
4. Mižáková A, Pipová M, Turek P. The occurrence of moulds in fermented raw meat products. Czech J Food Sci. 2002;20(3):89-94.

https://doi.org/10.17221/3515-CJFS

5. Ludemann V, Pose GN, Pollio ML, Segura J. Surface mycoflora of Argentinean dry fermented sausages and toxigenicity of Penicillium isolates. J Food Technol. 2004;2(4):288-92.

6. Wang X, Ma P, Jiang DF, Peng $Q$, Yang HY. The natural microflora of Xuanwei ham and the no-mouldy ham production. J Food Eng. 2006;77(1):103-11.

https://doi.org/10.1016/j.jfoodeng.2005.06.047

7. Papagianni M, Ambrosiadis I, Filiousis G. Mould growth on traditional Greek sausages and penicillin production by Penicillium isolates. Meat Sci. 2007;76(4):653-7. https://doi.org/10.1016/j.meatsci.2007.01.018

8. Sørensen LM, Jacobsen T, Nielsen PV, Frisvad JC, Koch AG. Mycobiota in the processing areas of two different meat products. Int J Food Microbiol. 2008;124(1):58-64. https://doi.org/10.1016/j.ijfoodmicro.2008.02.019

9. Castellari C, Quadrelli AM, Laich F. Surface mycobiota on Argentinean dry fermented sausages. Int J Food Microbiol. 2010;142(1-2):149-55.

https://doi.org/10.1016/j.ijfoodmicro.2010.06.016

10. Canel RS, Wagner JR, Stenglein SA, Ludemann V. Indigenous filamentous fungi on the surface of Argentinean dry fermented sausages produced in Colonia Caroya (Córdoba). Int J Food Microbiol. 2013;164(1):81-6. https://doi.org/10.1016/j.ijfoodmicro.2013.03.022

11. McMillin KW. Where is MAP going? A review and future potential of modified atmosphere packaging for meat. Meat Sci. 2008;80(1):43-65.

https://doi.org/10.1016/j.meatsci.2008.05.028

12. Gokoglu N, Yerlikaya P, Uran H, Topuz OK. The effect of modified atmosphere packaging on the quality and shelf life of frankfurter type-sausages. J Food Quality. 2010;33(S1):367-80. https://doi.org/10.1111/j.1745-4557.2010.00317.x

13. Tabanelli G, Montanari C, Grazia L, Lanciotti R, Gardini F. Effects of aw at packaging time and atmosphere composition on aroma profile, biogenic amine content and microbiological features of dry fermented sausages. Meat Sci. 2013;94(2):177-86. https://doi.org/10.1016/j.meatsci.2013.01.018

14. Summo C, Caponio F, Pasqualone A. Effect of vacuum-packaging storage on the quality level of ripened sausages. Meat Sci. 2006;74(2):249-54.

https://doi.org/10.1016/j.meatsci.2006.03.008

15. Liaros NG, Katsanidis E, Bloukas JG. Effect of the ripening time under vacuum and packaging film permeability on processing and quality characteristics of low-fat fermented sausages. Meat Sci. 2009;83(4):589-98.

https://doi.org/10.1016/j.meatsci.2009.07.006 
16. Summo C, Caponio F, Paradiso VM, Pasqualone A, Gomes T. Vacuum-packed ripened sausages: Evolution of oxidative and hydrolytic degradation of lipid fraction during longterm storage and influence on the sensory properties. Meat Sci. 2010;84(1):147-51.

https://doi.org/10.1016/j.meatsci.2009.08.041

17. Ministerial Resolution 37/2014. Buenos Aires, Argentina: Ministry of Agriculture, Livestock and Fisheries of the Argentine Nation; 2014 (in Spanish).

18. Pitt Jl, Hocking AD, editors. Fungi and food spoilage. Boston, MA, USA: Springer; 2009. https://doi.org/10.1007/978-0-387-92207-2

19. Argentine Food Code. Meat and related foods. Buenos Aires, Argentina: National Administration of Medicines, Food and Medical Technology (ANMAT); 2016 (in Spanish).

20. ISO 15213:2003. Microbiology of food and animal feeding stuffs - Horizontal method for the enumeration of sulfite-reducing bacteria growing under anaerobic conditions. Geneva, Switzerland: International Organization for Standardization (ISO); 2003.

21. International Commission on Microbiological Specifications for Foods (ICMSF). Microorganisms in food. Zaragoza, Spain: Acribia; 2000 (in Spanish).

22. ISO 13299:2016. Sensory analysis - Methodology - General guidance for establishing a sensory profile. Geneva, Switzerland: International Organization for Standardization (ISO); 2016.

23. ISO 8586:2012. Sensory analysis - General guidelines for the selection, training and monitoring of selected assessors and expert sensory assessors. Geneva, Switzerland: International Organization for Standardization (ISO); 2012.

24. Pearson D, Cox HE, editors. The chemical analysis of foods. Edinburgh, UK: Churchill Livingstone; 1976.

25. InfoStat, v. 2017, The National University of Córdoba, Córdoba, Argentina; 2017. Available from: http://www.infostat. com.ar/.

26. Ordóñez JA, Hierro EM, Bruna JM, de La Hoz L. Changes in the components of dry-fermented sausages during ripening. Crit Rev Food Sci. 1999;39(4):329-67. https://doi.org/10.1080/10408699991279204

27. Toldrá F, Hui YH. Dry-fermented sausages and ripened meats: An overview. In: Toldrá F, Hui YH, Astiasarán I, Sebranek JG, Talon R, editors. Handbook of fermented meat and poultry. Chichester, UK: John Wiley \& Sons, Ltd; 2014. pp. 1-6.

https://doi.org/10.1002/9781118522653.ch1

28. Brown W. On the germination and growth of fungi at various temperatures and in various concentrations of oxygen and of carbon dioxide. Ann Bot. 1922;36(2):257-83. https://doi.org/10.1093/oxfordjournals.aob.a089805

29. Fellows $\mathrm{H}$. The influence of oxygen and carbon dioxide on the growth of Ophiobolus graminis in pure culture. J Agric Res. 1928;37:349-55.
30. Macy $\mathrm{H}$. Some of the factors influencing the growth of molds in butter [PhD Thesis]. Ames, IA, USA: lowa State University; 1929.

https://doi.org/10.31274/rtd-180813-15673

31. Ruyle EH, Pearce WE, Hays GL Prevention of mold in kettled blueberries in no. 10 cans. J Food Sci. 1946;11(3):274-9. https://doi.org/10.1111/j.1365-2621.1946.tb16351.x

32. Drapron R. Enzyme activity as a function of water activity. In: Simatos D, Multon JL, editors. Properties of water in foods. Dordrecht, The Netherlands: Springer; 1985. pp. 171-90. https://doi.org/10.1007/978-94-009-5103-7_11

33. Chávez R, Fierro F, García-Rico RO, Laich F. Mold-fermented foods: Penicillium spp. as ripening agents in the elaboration of cheese and meat products. In: Leitão $A L$, editor. Mycofactories. Emirate of Sharjah, UAE: Bentham Science Publisher; 2011. pp. 73-98.

https://doi.org/10.2174/978160805223311101010073

34. Ščetar M, Kovačić E, Kurek M, Galić K. Shelf life of packaged sliced dry fermented sausage under different temperature. Meat Sci. 2013;93(4):802-9.

https://doi.org/10.1016/j.meatsci.2012.11.051

35. Cattaneo P, Stella LS, Pensatene A, Cantoni C. Alterations of dry salami prepared with swine DFD meat. Arch Vet Ital. 2003;54:11-20 (in Italian).

36. Comi G, lacumin L. Ecology of moulds during the pre-ripening and ripening of San Daniele dry cured ham. Food Res Int. 2013;54(1):1113-9.

https://doi.org/10.1016/j.foodres.2013.01.031

37. lacumin L, Manzano M, Panseri S, Chiesa L, Comi G. A new cause of spoilage in goose sausages. Food Microbiol. 2016;58:56-62.

https://doi.org/10.1016/j.fm.2016.03.007

38. Parris N, Foglia TA. Simplified alcoholic extraction procedure for ammonia in meat tissue. J Agric Food Chem. 1983;31(4):887-9.

https://doi.org/10.1021/jf00118a054

39. Seefeldt KE, Weimer BC. Diversity of sulfur compound production in lactic acid bacteria. J Dairy Sci. 2000;83(12):2740-6. https://doi.org/10.3168/jds.S0022-0302(00)75168-X

40. Joffraud JJ, Leroi F, Roy C, Berdague JL. Characterization of volatile compounds produced by bacteria isolated from the spoilage flora of cold-smoked salmon. Int J Food Microbiol. 2001;66(3):175-84.

https://doi.org/10.1016/S0168-1605(00)00532-8

41. Herrero AM, Ordóñez JA, de Avila R, Herranz B, de la Hoz L, Cambero MI. Breaking strength of dry fermented sausages and their correlation with texture profile analysis (TPA) and physico-chemical characteristics. Meat Sci. 2007;77(3):331-8. https://doi.org/10.1016/j.meatsci.2007.03.022 